This is the peer reviewed version of the following article: Harder R, Peters GM, Molander S, Ashbolt NJ, Svanström M (2016) Including pathogen risk in life cycle assessment: the effect of modelling choices in the context of sewage sludge management, International Journal of Life Cycle Assessment 21(1):60-69. The final publication is available at Springer via http://www.dx.doi.org/10.1007/s11367-015-0996-2.

\title{
Including pathogen risk in life cycle assessment: the effect of modelling choices in the context of sewage sludge management
}

\author{
Robin Harder ${ }^{\mathrm{a}}$, Gregory M Peters ${ }^{\mathrm{a}}$, Sverker Molander ${ }^{\mathrm{b}}$, Nicholas J Ashbolt ${ }^{\mathrm{c}}$, Magdalena \\ Svanström ${ }^{\mathrm{a}}$ \\ ${ }^{a}$ Chemical Environmental Science, Department of Chemistry and Chemical Engineering, Chalmers University \\ of Technology, SE-412 96 Gothenburg, Sweden \\ ${ }^{\mathrm{b}}$ Environmental Systems Analysis, Department of Energy and the Environment, Chalmers University of \\ Technology, SE-412 96 Gothenburg, Sweden \\ c School of Public Health, University of Alberta, Edmonton, Alberta T6G 2G7, Canada
}

\begin{abstract}
Purpose Recent attempts to include adverse effects of pathogens on human health in life cycle assessment (LCA) have focused on integrating results obtained through quantitative microbial risk assessment (QMRA) as an impact category in LCA. This study aims to investigate whether the use of QMRA can be an adequate way of integrating pathogen impact potential in LCA, and to quantify how pathogen impact potential is affected by choices regarding model structure and mathematical relationships used.

Method This study is performed for the context of sewage sludge management and is based on pathogen concentrations in treated sludge reported in the literature. Eight reference pathogens were included in order to address important microbial groups. The pathogen impact potential associated with land application of sewage sludge was quantified based on a QMRA model for eight distinct exposure pathways. The modelling choices investigated were linearisation of dose-response and severity assessment, and different modelling approaches and parameter choices in fate and exposure assessment.

Results and discussion The linearisation of effect and severity assessment had a minor impact on the results for exposure pathways where pathogen doses were low, but had a major impact where pathogen doses were high. The assumptions regarding fate and exposure conditions, such as pathogen decay time, number of individuals exposed, and frequency of exposure, had a significant effect on overall pathogen impact potential. If pathogen impact potential is to be integrated in LCA, a range of different parameterisations for each exposure event may be warranted rather than only the one with the highest risk per individual exposed as commonly reported for QMRAs. This is also in line with the ordinary LCA practice of focusing on average rather than extreme conditions.

Conclusions and recommendations This study suggests that the use of QMRA can be an adequate way of integrating adverse effects of pathogens on human health in LCA. However, analysts should be careful when choosing model parameters such as the number of people exposed or the frequency of exposure, as LCA may require a different parameterisation than an ordinary risk assessment (RA). Therefore, a direct integration of the results of a QMRA study into LCA may be problematic. Also, in order to avoid potential bias, analysts should carefully consider whether or not pathogen impact potential and human toxicity potential need to be estimated based on a similar set of exposure pathways.
\end{abstract}

Keywords: LCA, LCIA, QMRA, microbial risks, biosolids, human toxicity

Address correspondence to: Robin Harder, robin.harder@wetryharder.ch 
This is a peer reviewed manuscript accepted for publication in the International Journal of Life Cycle Assessment. The final publication is available at Springer via http://www.dx.doi.org/10.1007/s11367-015-0996-2.

\section{Introduction}

In the context of wastewater and sewage sludge management, human health risks associated with hazardous chemicals and microorganisms present in wastewater and sewage sludge are of particular concern. The health risks related to particular wastewater and sewage sludge management options are commonly quantified in risk assessment studies (e.g. Brooks et al. 2012; Gale 2005; Schoen et al. 2014). Toxic effects of chemicals on human health (human toxicity) have also been assessed in lifecycle assessment (LCA) studies (for recent reviews of LCA studies in the context of wastewater and sewage sludge management the reader is referred to Corominas et al. 2013 and Yoshida et al. 2013), with a focus on wider impacted regions compared to local impacts addressed by risk assessment (RA) studies. Life cycle impact assessment (LCIA) models to assess human toxicity are under continuous development (Hauschild et al. 2013). However, there are currently no standard LCIA models available for the inclusion of adverse effects of pathogens on human health (pathogen impact potential) in LCA. As a result, pathogen impact potential is rarely included in LCA studies.

In recent years, a number of attempts have been made to integrate quantitative microbial risk assessment (QMRA) results into an LCA framework (Aramaki et al. 2006; Harder et al. 2014; Heimersson et al. 2014; Kobayashi et al. 2015; Larsen et al. 2009). These studies essentially estimated the burden of disease associated with the exposure of humans to pathogens as a result of wastewater and sludge management operations for a varying number of pathogens and exposure pathways based on QMRA. Hereby, the burden of disease was expressed in terms of disability-adjusted life years (DALYs), a concept developed for the World Health Organisation (Murray 1994). This pathogen-related burden of disease was then presented in an LCA framework and treated as an LCA impact category. Clearly, pathogen impact potential and human toxicity potential both represent potential impacts on human health, and can be expressed in terms of DALYs (Gao et al. 2015). But is the integration of QMRA results in an LCA framework an adequate way of addressing the adverse effects of pathogens on human health in LCA?

Traditionally, LCIA does not take into account the time-space distribution of stressors and effects. Currently available LCIA models for human toxicity of chemicals (e.g. the USEtox ${ }^{\mathrm{TM}}$ model) for instance usually are steady-state fugacity-based compartment models. The compartments included in fate assessment often represent compartments at larger spatial scales (e.g. the regional or global scale), although efforts are made to increase the level of spatial resolution and differentiation. Exposure assessment may not include occupational exposure and usually does not address different sub-populations (Rosenbaum et al. 2011). Effect assessment is usually based on linear mathematical relationships. But more importantly, parameter values in fate and exposure assessment usually represent routine operations under realistic average conditions. This approach is in line with common practice in LCA, namely to base the comparison of the performance of different product or service systems, or different life cycle phases of a product or service system, on a typical situation when technical systems operate according to the design specifications.

When it comes to adverse effects of pathogens on human health, however, the operation conditions with significant impacts may be events where processes do not work as they are supposed to. These are the conditions commonly addressed in QMRA. Because of a significant variability in the procedures and locations used for wastewater and sewage sludge management, the assessment of pathogen risk using QMRA is usually characterised by a high level of spatial and temporal specificity regarding transport, fate, and exposure conditions (Haas et al. 2014). Exposure assessment often includes occupational, recreational, as well as residential activities. Moreover, many of the mathematical relationships used in effect assessment are non-linear. In QMRA, parameter values in fate and exposure assessment often represent realistic worst-case conditions, aiming at identifying critical exposure pathways, exposure conditions, and sub-populations (Haas et al. 2014). In the context of wastewater and sewage sludge management, the frequency of the occurrence of operating conditions where the system does not work according to the design specifications may warrant consideration of adverse effects of pathogens on human health also in LCA. In LCA, however, the focus is on the overall impact for a given human population rather than on risks for specific members of a given human population. When it comes to addressing adverse effects of pathogens on human health in LCA, two questions thus are of interest and are addressed by the present study.

The first question is whether the mathematical relationships and the model structure of QMRA can be simplified and made more generic, similar to the development of generic LCIA models for human toxicity of chemicals starting from mathematical relationships established within chemical RA. To this end, the aim of the 
This is a peer reviewed manuscript accepted for publication in the International Journal of Life Cycle Assessment. The final publication is available at Springer via $h t t p: / / w w w . d x . d o i . o r g / 10.1007 / s 11367-015-0996-2$.

present study was to identify and explore possible modifications to the mathematical relationships and model structure applied in QMRA. The modifications identified and investigated in this study were inspired by the model structure and mathematical relationships underlying the USEtox ${ }^{\mathrm{TM}}$ model (Henderson et al. 2011; Rosenbaum et al. 2011). It should be noted that other LCIA methods for the characterisation of human toxicity, such as ReCiPe (Goedkoop et al. 2009), could have served as a starting point, but were not considered different enough in structure to warrant further study.

The second question is how pathogen impact potential is affected by different modelling choices pertaining to the mathematical relationships and model structure applied. In the present study, this comparison was made for eight exposure pathways related to land application of sewage sludge. The context of land application of sewage sludge was chosen because it is considered one option for recycling nutrients to productive land, alongside a range of more technical alternatives that involve extraction of nutrients from sludge or from solids remaining after partial or complete sludge oxidation (e.g. supercritical water oxidation, incineration). Land application of sewage sludge has been debated in Sweden (Bengtsson and Tillman 2004) and elsewhere for many years due to concerns about inorganic pollutants (e.g. heavy metals), organic pollutants (e.g. industrial chemicals, pharmaceutical residues, and hormones), and pathogens (e.g. bacteria, viruses, and parasites) present in the sludge.

Based on the findings from the case study on sewage sludge management, the present study provides recommendations on how to include pathogen risk in LCA, also in contexts other than sewage sludge management.

\section{Methods}

\subsection{Baseline model}

The baseline model follows a classical QMRA approach where each exposure pathway is modelled individually and effect assessment is based on non-linear dose-response relationships. Which model is used depends on the pathogen under consideration (Online Resource 1). Dose-response relationships for pathogens describe the relationship between a given pathogen dose per exposure event $\left(D_{e}\right)$ and the corresponding probability of infection (or illness) per exposure event $\left(P_{e}\right)$. In QMRA, dose-response relationships for pathogens usually are represented by non-linear mathematical relationships, such as the exponential model or a beta-Poisson model (Online Resource 1). The exposure pathways relevant for land application of sewage sludge as well as the mathematical relationships in the baseline model were largely based on Brooks et al. (2012) and Gale (2005) (further details are provided in Online Resource 1). The number of individuals exposed $\left(\mathrm{n}_{\text {ind }}\right)$ and the frequency of exposure $\left(f_{\text {exp }}\right)$ were largely based on Westrell et al. (2004), who investigated a wastewater treatment system treating $12500 \mathrm{~m}^{3}$ wastewater per day on average (serving 28600 people), and consisting of primary and secondary treatment (activated sludge process with biological nitrification-denitrification and chemical phosphorus removal), tertiary treatment (constructed wetland), anaerobic sludge digestion, and land application of digested sewage sludge (further details are provided in Online Resource 1). The reference pathogens included in the current study were Campylobacter jejuni, Salmonella enterica (non-typhi), Listeria monocytogenes, pathogenic Escherichia coli (strain O157:H7), human infectious Adenovirus, human infectious Enterovirus (represented by Coxsackie B virus), Giardia lamblia, and Cryptosporidium spp. The receptors covered are adults and children (exposed to pathogens through accidental, intentional, or routine ingestion or dermal contact during occupational, recreational, or residential activities) (see Table 1 and Figure 1).

\subsection{Modifications regarding mathematical relationships used in effect and severity assessment}

Linearisation of dose-response relationships (modification 1)

In the USEtox ${ }^{\mathrm{TM}}$ model, the dose-response relationships for chemicals are represented by a linear mathematical relationship. The human-toxicological effect factor for chemicals is calculated under the assumption of linearity in dose-response between zero and the point $\mathrm{ED}_{50}$ at which the lifetime disease probability is 0.5 (Huijbregts et al. 2010). In mathematical terms, the analogous modification to the baseline model would be the replacement of the exponential or beta-Poisson dose-response model with a linear one (Equation 1), where $\mathrm{ID}_{50}$ represents the dose where the probability of infection (or illness) is 0.5 . 


$$
P_{e}=\frac{0.5}{I D_{50}} \cdot D_{e}
$$

The linearisation shown in Equation 1 is expected to cause an underestimation of the probability of infection (or illness) for low pathogen doses $\left(D_{e}<I D_{50}\right)$ and an overestimation for high pathogen doses $\left(D_{e}>\right.$ $I D_{50}$ ). For a graphical representation of the original (i.e. exponential or beta-Poisson) and the modified (i.e. linearised) dose-response models see Figure 2 and Online Resource 1.

It is important to realise that the probability of infection (or illness) per exposure event $\left(P_{e}\right)$ can exceed 1 in Equation 1. Also the mathematical formulation of the linearised concentration-response model reported in the USEtox $^{\mathrm{TM}}$ user manual (Huijbregts et al. 2010) is unbounded and it would appear that it extends linearly also for probabilities above 0.5 even though the assumption of linearity is applied only for disease probabilities below 0.5 . In the case of human toxicity of chemicals, this is not an issue in practice, as the assessment concerns lifetime disease probabilities resulting from chronic exposure. The emissions of chemicals considered in a given LCA study only constitute marginal contributions well below a lifetime disease probability of 0.5 . In the case of pathogen impact potential, however, the probability of infection (or illness) is related to acute effects, and the emission of pathogens considered in a given LCA study can easily reach above a disease probability of 0.5 . When investigating pathogen impact potential, it is therefore useful to see linearisation of dose-response relationships as consisting of two components: the actual linearisation on the one hand, and the removal of the upper boundary (i.e. $P_{\max }=1$ ) on the other hand. In order to be able to judge the effect of these two components individually, a piece-wise linearisation (Equation 2) was considered as an alternative to the full linearisation (Equation 1).

$$
P_{e}=\min \left(\frac{0.5}{I D_{50}} \cdot D_{e}, 1\right)
$$

The piece-wise linearisation of the dose-response relationship (Equation 2) will henceforward be referred to as modification 1a and it aimed at investigating the effect of changing the shape of the dose-response curve whilst retaining an upper boundary (i.e. $\left.P_{e, \max }=1\right)$ for the probability of infection or illness $\left(P_{e}\right)$. The removal of the upper limit for the probability of infection or illness, leading to a full linearisation of the dose-response relationship (Equation 1), will henceforward be referred to as modification 1b.

\section{Linearisation of severity assessment relationships (modification 2)}

In order to convert the probability of infection or illness $\left(P_{e}\right)$ per exposure event into a burden of disease, the first step is to calculate the annual probability of infection or illness $\left(P_{a}\right)$, taking into account the number of exposure events of a certain type an individual is exposed to during a year $\left(n_{e}\right)$. In mathematical terms, linearisation of severity assessment relationships corresponds to replacing Equation 3 used in the baseline model with Equation 4.

$$
\begin{aligned}
& P_{a}=1-\left(1-P_{e}\right)^{n_{e}} \\
& P_{a}=P_{e} \cdot n_{e}
\end{aligned}
$$

On a conceptual level, this modification implies that the annual probability of infection or illness $\left(P_{a}\right)$ no longer represents the probability of one individual becoming subject to infection or illness once or more in a year (i.e. Equation 3 counts an individual infected several times a year as one case of infection), but the actual number of infections, neglecting immunity effects and the duration of an infection (i.e. Equation 4 counts an individual infected on two successive months as two cases of infection). For small probabilities of infection or illness per exposure event $\left(P_{e}\right)$, the annual probabilities of infection or illness $\left(P_{a}\right)$ calculated using Equation 3 and Equation 4 , and hence the annual number of cases of infection or illness $\left(N_{a}\right)$, are nearly identical. For larger probabilities of infection or illness per exposure event $\left(P_{e}\right)$, however, the results from Equation 4 are much larger than from Equation 3. 
This is a peer reviewed manuscript accepted for publication in the International Journal of Life Cycle Assessment. The final publication is available at Springer via $h t t p: / / w w w . d x . d o i . o r g / 10.1007 / s 11367-015-0996-2$.

Investigating the effects of linearization in effect and severity assessment

In order to investigate the effect of linearisation on estimated pathogen risk, five model variants were conceived. Model variant BL represents the baseline model (i.e. classical QMRA approach with effect assessment based on non-linear mathematical relationships) whereas model variants M1-M4 represent distinct combinations of the first two model modifications (Table 2).

\subsection{Modifications regarding the overall model structure of fate and exposure assessment}

Exclusion of certain exposure pathways from the analysis (modification 3)

Not all exposure pathways covered by the baseline model for pathogens are covered in the USEtox ${ }^{\mathrm{TM}}$ model for chemicals. For instance, occupational exposure and accidental exposure by children to sewage sludge at wastewater treatment facilities and on agricultural fields are not considered in the USEtox ${ }^{\mathrm{TM}}$ model. Rather, the USEtox $^{\mathrm{TM}}$ model only considers exposure pathways originating in compartments at the continental and global scales. Further, all humans in the respective region are assumed to be exposed to the steady-state concentrations by breathing air, drinking water, and ingesting food products. No distinction is made between sub-populations. Given the set of exposure pathways considered in this study in the context of land application of sewage sludge, Modification 3 consists of limiting the set of exposure pathways to the consumption of produce grown on sludge-amended land (exposure pathway E8 in Table 1). This exposure pathway is the only one considered in this study that is included in the USEtox ${ }^{\mathrm{TM}}$ model. In order to investigate the effect of modification 3 , the model results for each model variant were reported separately for exposure pathway E8 in addition to the aggregated results for exposure pathways E1-E8 and E1-E7, respectively (Table 3).

\section{Different modelling approaches and parameter choices regarding exposure pathway E8}

For exposure pathway E8, the effect of different modelling approaches and parameter choices was investigated. Particular attention was given to the assumptions regarding exposure parameters (i.e. amount of produce consumed per individual exposed, frequency of exposure, number of individuals exposed). Four scenarios were investigated (Table 4).

The parameterisation in scenarios S1 and S2 was based on Brooks et al. (2012) regarding the amount of vegetables (grown on sewage sludge-amended land) eaten per individual $\left(r_{\text {ing }}\right)$ and based on Westrell et al. (2004) regarding the number of individuals exposed $\left(\mathrm{n}_{\text {ind }}\right)$ and the frequency of exposure through consumption $\left(f_{\text {exp }}\right)$. In scenario $\mathrm{S} 1$, the decay time in soil $\left(t_{s}\right)$ and on crops $\left(t_{c}\right)$ were chosen to represent an ideal situation with nominal system performance (i.e. the system works as it is supposed to, the time lag between sludge spreading and harvesting is $t_{s}=90 \mathrm{~d}$ and the time lag between harvesting and consumption is $\left.t_{c}=10 \mathrm{~d}\right)$. In scenario $\mathrm{S} 2$, the decay time on soil and crops were chosen to represent a bypass situation (i.e. the time lag between sludge spreading and harvesting is $\mathrm{t}_{\mathrm{s}}=5 \mathrm{~d}$ and the time lag between harvesting and consumption is $\mathrm{t}_{\mathrm{c}}=0 \mathrm{~d}$ ).

The parameterisation in scenario S3 is based on Gale (2005) $\left(\mathrm{r}_{\mathrm{ing}}, \mathrm{n}_{\text {ind }}, \mathrm{f}_{\mathrm{exp}}\right)$. Gale (2005) assumed that 1150 000 people in the UK consume vegetables crops (all year) grown on land treated with sewage sludge; this estimate was based on the application of 520000 tonnes of dry sewage sludge to agricultural land. In the current study, sewage sludge production is estimated to be 2150 tonnes of dry sludge, based on the assumption of a sludge production of $75 \mathrm{~kg}$ per capita per year and 28600 people connected to the treatment plant. Based on the study of Gale (2005), hence assuming conditions similar to the UK, the number of people exposed in the present study would be 4 750. The decay time in soil and on the crops were chosen to represent an ideal situation with nominal system performance. For scenarios S1-S3, the overall burden of disease could be calculated for each model variant (BL and M1-M4).

Scenario S4 represents a different approach and did not require the specification of the amount of vegetables (grown on sewage sludge-amended land) eaten per individual $\left(r_{i n g}\right)$, the frequency of exposure through consumption $\left(f_{\exp }\right)$, nor the number of individuals exposed $\left(\mathrm{n}_{\mathrm{ind}}\right)$. Rather, this approach of calculating the burden of disease (BoD) associated with land application of sewage sludge started from the amount of pathogens emitted $\left(p_{e m}\right)$, which is a function of the pathogen concentration in the sewage sludge $(c)$ and the application rate (AR). A fraction of these pathogens was assumed to remain infectious in the soil after decay processes $\left(f_{s}\right)$, a sub-fraction of these transferred to the crop $\left(f_{s c}\right)$, and yet another sub-fraction remained on the crop after further decay processes $\left(f_{c}\right)$. Essentially, this approach was based on linear mathematical relationships and attempted to calculate an intake fraction (iF), which can then be multiplied with an effect factor (EF) based on $I D_{50}$ and the 
This is a peer reviewed manuscript accepted for publication in the International Journal of Life Cycle Assessment. The final publication is available at Springer via $h t t p: / / w w w . d x . d o i . o r g / 10.1007 / s 11367-015-0996-2$.

burden of disease per case of infection $\left(\mathrm{BoD}_{\text {case }}\right)$. The model variant applied to scenario $\mathrm{S} 4$ is referred to as model variant ALT and is represented in Equation 5.

$$
B o D=\underbrace{c \cdot A R}_{p_{\text {em }}} \cdot \underbrace{\underbrace{10^{-d_{s} \cdot t_{s}}}_{f_{s}} \cdot \underbrace{k_{s, c} \cdot k_{c, c}}_{f_{s c}} \cdot \underbrace{10^{-d_{c}} \cdot t_{c}}_{f_{c}}}_{C F} \cdot \underbrace{\frac{0.5}{I D_{50}} \cdot B o D_{c a s e}}_{E F}
$$

\subsection{Model implementation}

All model variants and modelled scenarios started from the pathogen concentrations in treated (digested and dewatered) sewage sludge reported in the literature (Bofill-Mas et al. 2006; Gale 2005) (Online Resource 1). The pathogen concentrations and parameter values are provided in Online Resource 1. All model variants were built in both MATLAB R2014a and Microsoft Excel 2011 for validation purposes.

\section{Results}

\subsection{The effect of linearisation of effect and severity assessment relationships}

Aggregated effects at the level of the overall burden of disease

For each model variant, the burden of disease was calculated and aggregated over all exposure pathways and reference pathogens (Table 3). Modification 1a (i.e. linearisation of dose-response relationships while retaining the upper boundary of the probability of infection or illness) seemed to have little effect overall (M1 versus BL). Modification 2 (i.e. linearisation of severity assessment relationships) increased the overall pathogen impact potential in model variants M2 and M3 by a factor of 7 compared to the baseline model variant BL. Modification $1 b$ (i.e. full linearisation of dose-response relationships) had the most pronounced effect, as the pathogen impact potential in model variant M4 was increased another factor of 84 compared to model variant M3. Note that these findings did not apply to all individual combinations of pathogen and exposure pathway but relate to the overall results.

\section{Effects at the level of distinct combinations of pathogen and exposure pathway}

For some distinct combinations of pathogen and exposure pathway, the different model variants provided similar results (see pathogens P2 and P7 in Figure 3). For other combinations of pathogen and exposure pathway, however, deviations between model variants were significant (see pathogen P1 in Figure 3). The detailed results obtained for the different model variants are provided in Online Resource 1 for every combination of pathogen and exposure pathway.

For exposure frequencies $\left(f_{\text {exp }}\right)$ considerably above 1 , linearisation of severity assessment (modification 2 ) led to a higher burden of disease estimate in model variant M2 in comparison to the baseline model variant BL, and in model variants M3 and M4 in comparison to model variant M1. In other words, modelling one individual exposed ten times per year as ten individuals exposed once per year will yield a higher burden of disease estimate. This effect was more pronounced at higher exposure frequencies $\left(f_{\text {exp }}\right)$ and at higher pathogen doses $\left(D_{e}\right)$. For pathogen doses below (respectively above) $\mathrm{ID}_{50}$, as expected, piece-wise linearisation of the doseresponse relationship (i.e. linearisation with retaining the upper boundary of the probability of infection or illness) (modification 1a) led to a lower (respectively higher) burden of disease estimate in model variant M1 in comparison to the baseline model variant BL, and in model variants M3 and M4 in comparison to model variant M2. Although linearisation of severity assessment (modification 2) and piece-wise linearisation of dose-response assessment (modification 1a) did have an effect on pathogen risk, this effect was relatively small.

The effect of the removal of the upper boundary of the probability of infection or illness as a result of full linearisation of dose-response assessment (modification 1b), however, was potentially significant. For combinations of pathogen and exposure pathway subject to high pathogen doses per individual exposed, the removal of the upper boundary for the probability of infection or illness (modification 1b) led to a considerably higher burden of disease estimate in model variant M4 in comparison to model variant M3 (particularly for exposure pathway E2). 
3.2 The effect of adaptations to the overall model structure and variation in fate and exposure assessment

For each model variant, the burden of disease was calculated for exposure pathways E1-E7, E1-E8, and E8 separately (Table 3). The initial model parameterisation of exposure pathway E8 (scenario S1) essentially assumed that 500 individuals eat 292 grams of contaminated vegetables twice a year, and that vegetables are harvested 90 days after sludge application and eaten 10 days after harvest. For this model parameterisation, the contribution of exposure E8 was negligible. As there is more produce available from sludge-amended fields than consumed in this scenario, the analysis follows the implicit assumption that all remaining produce is free of pathogens. If exposure pathway E8 is parameterised differently (Table 4), its contribution to the overall burden of disease becomes more significant, particularly for scenario S2 (bypass situation) and scenario S4 (alternative modelling approach using model variant ALT). Yet, it is difficult to draw general conclusions about the significance of exposure pathway E8 as also other exposure pathways may be modelled and parameterised differently.

\section{Discussion}

\subsection{Sources of uncertainty}

This study explored several modifications to the mathematical relationships and model structure underlying QMRA with intent to make the characterisation of pathogen impact potential more akin to traditional LCIA models for the characterisation of human toxicity potential. It is important to recall that this study is based on pathogen concentrations and a set of exposure pathways described in the literature rather than the actual pathogen concentrations and exposure pathways characteristic of a specific site. Therefore, different results may have been obtained if different sludge qualities or a different set of exposure pathways had been considered. Nevertheless, the main findings of this study regarding the effect of linearisation in effect assessment can be said to be robust towards these sources of uncertainty. Regarding fate and exposure assessment, this study indicated that the choice of exposure pathways, modelling approach and model parameterisation represent major sources of uncertainty. Different assumptions regarding model parameters (i.e. pathogen decay time, number of individuals exposed, frequency of exposure) strongly influenced the estimated pathogen risk. Although only one exposure pathway was investigated in detail regarding the effect of modelling approach and parameterisation, this finding is deemed to be valid also for other exposure pathways and contexts. Finally, a potentially relevant aspect that was not addressed in the present study is the use of dynamic model concepts that address immunity and secondary spread (Eisenberg et al. 2002; Eisenberg et al. 2004; Eisenberg et al. 2008; Soller 2009). Neither was specific attention given to the uncertainties related to the estimation of pathogen concentration in sewage sludge through different sampling procedures.

\subsection{Towards good practice for the integration of pathogen risk in LCA}

\section{Linearisation of mathematical relationships not always possible}

When addressing pathogen risks related to exposure pathways with relatively low pathogen doses per exposure event, linearisation of dose-response relationships appears possible. For example, for the consumption of produce grown on sludge-amended land, the calculation model for pathogen risk could be conceived in a manner similar to models for human toxicity of chemicals (e.g. the USEtox ${ }^{\mathrm{TM}}$ model). The use of linear mathematical relationships in effect assessment would enable the combination of an effect factor (EF) based on a linear doseresponse relationship with a pathogen intake fraction (iF). Thus, for the consumption of produce grown on sludge-amended land, it would be possible to calculate a characterisation factor (CF) representing a certain sewage sludge application regime (i.e. a given application rate, decay rates and time lags between land application and harvest) (Equation 5). When addressing pathogen risks related to occupational exposures and other exposures with potentially higher pathogen doses per exposure event, however, full linearisation of doseresponse relationships (modification 1b) appears inappropriate because it could lead to an overestimation of the pathogen impact potential by several orders of magnitude. 
This is a peer reviewed manuscript accepted for publication in the International Journal of Life Cycle Assessment. The final publication is available at Springer via $h t t p: / / w w w . d x . d o i . o r g / 10.1007 / s 11367-015-0996-2$.

\section{Implications for scaling to a functional unit}

In LCA, scaling to a functional unit usually takes place before fate, exposure and effect assessment. In combination with LCIA models for human toxicity of chemicals, this is acceptable, as all mathematical relationships are linear and the emissions of chemicals considered in a given LCA study usually are marginal contributions to a lifetime disease probability. The situation is different for pathogens, where the effects considered are acute rather than chronic. In those cases where full linearisation of dose-response relationships is inappropriate for the estimation of pathogen impact potential, the nonlinearity implies that pathogen doses need to be expressed in absolute terms rather than as marginal increase. This in turn implies that pathogen emissions cannot be scaled to a functional unit before fate, exposure and effect assessment, as otherwise nonlinearities in the dose-response relationship would not be properly accounted for. Still, scaling to a functional unit is possible, it just needs to be done after effect assessment (Harder et al. 2015).

\section{Overall model structure and parameterisation}

Broadly speaking, the assessment of adverse effects related to pathogens requires the identification of a set of exposure pathways to be considered in the analysis. For each exposure pathway, over the course of time there occur a number of exposure events, during each of which the receptor is exposed to a certain pathogen dose $\left(D_{e}\right)$. Furthermore, a certain number of individuals are affected, and specific individuals may get exposed once or more. This simply means that, for each exposure pathway considered in a given study, the corresponding exposure events can in principle be parameterised in different ways, reflecting different exposure conditions. For example, one parameterisation may represent nominal system performance while another parameterisation may represent periods of poorer system performance for the same exposure pathway. The usual rationale followed in a QMRA framework is to limit the analysis to one specific parameterisation of exposure event per exposure pathway. The parameters are chosen such as to reflect realistic worst-case circumstances in terms of the highest burden of disease per individual exposed. For this critical exposure event, the analyst defines the pathogen dose $\left(D_{e}\right)$, the number of individuals exposed $\left(n_{\text {ind }}\right)$, and the number of exposure events these individuals are exposed to during a year $\left(f_{\exp }\right)$. Considering only one critical parameterisation of exposure event is perfectly acceptable and appropriate in a QMRA framework, yet there is a general move towards more stochastic assessments that cover a suite of reference pathogens (Sales-Ortells and Medema, 2015).

In an LCA framework, however, considering only the parameterisation of exposure event with the highest burden of disease per individual exposed may not be appropriate. Say one worker gets exposed to a given pathogen dose, corresponding to a probability of infection of 0.7 , once per year (event A1). Say another twenty workers each get exposed to a third of this pathogen dose, corresponding to a probability of infection of 0.3 , once per year (event A2) through the same exposure pathway (exposure pathway A). In a QMRA framework, where the focus is on risks for specific members of a given human population, exposure event A1 clearly is the critical one. In an LCA framework, however, where the focus is on overall impact, exposure event A2 may be the critical one, as the larger number of people exposed may lead to a higher overall burden of disease despite the less critical parameterisation of this exposure event (from the perspective of one individual exposed).

Because LCA focuses on overall impacts (i.e. the overall burden of disease for pathogen impact potential), it would in principle be necessary to consider a broader set of parameterisations for each individual exposure event. This set of parameterisations may then reflect a variety of exposure conditions during both nominal system performance and periods of poorer system performance or system mismanagement (bypass situations). The different exposure conditions could then be weighted before including the results in an LCA framework.

\section{Comparability of pathogen impact potential and human toxicity potential in an LCA framework}

The QMRA model for pathogen risk investigated in this study covered more exposure pathways than the USEtox $^{\mathrm{TM}}$ model for the assessment of chemical risk. Even if parameterised in accordance with the principles applied in an LCA framework, the pathogen risk estimated using such a QMRA model may therefore not be directly comparable with chemical risk estimated based on the USEtox ${ }^{\mathrm{TM}}$ model. Including a broader set of exposure pathways for pathogens than for chemicals may introduce bias if chemical risk and pathogen risk are compared to each other. Such bias would essentially result from the inclusion of certain exposure pathways for pathogen risk whilst the same exposure pathways are neglected for chemical risk. Hence, also the aggregation of the respective burden of disease estimates for pathogen risk and chemical risk may be problematic. It therefore appears worthwhile to investigate the influence of modelling choices also for chemical risk through a 
This is a peer reviewed manuscript accepted for publication in the International Journal of Life Cycle Assessment. The final publication is available at Springer via $h t t p: / / w w w . d x . d o i . o r g / 10.1007 / s 11367-015-0996-2$.

comparison of the chemical risks estimated using LCIA models such as the USEtox ${ }^{\mathrm{TM}}$ model with chemical risks estimated using a model structure more similar to QMRA. Such fate and transport models would be based on site-specific exposure pathways rather than multimedia fate and transport models covering larger spatial scales. Hence, using site-specific data would provide a second perspective on the question whether the integration of pathogen impact potential (assessed using mathematical relationships based on QMRA) in an LCA framework alongside human toxicity potential (assessed using fugacity-based LCIA models) introduces bias.

\section{Conclusions and recommendations}

When combining QMRA and LCA, analysts should be aware of the differences between the QMRA and LCA frameworks. Based on this study and previous expertise of the authors, we argue that the direct integration of the results of a QMRA study into an LCA framework can be problematic. However, the use of QMRA as a substitute for non-existent LCIA models for the estimation of pathogen risk can be an adequate way of integrating pathogen risk in an LCA framework alongside LCIA models for the assessment of other potential impacts on human health, but generally only if the model is parameterised in accordance with the principles applied in the LCA framework. Hereby, analysts should be particularly careful when making assumptions regarding exposure conditions such as pathogen decay, the number of people exposed, and the frequency of exposure. These assumptions strongly influence the estimated pathogen risk. Finally, analysts should carefully consider whether the quantification of chemical risks and pathogen risks needs to be based on a similar set of exposure pathways, or rather on pathways of highest risk for each hazard class - with specific identification of such.

\section{Acknowledgements}

This project has received funding from the European Union's Seventh Programme for research, technological development and demonstration under grant agreement No 265156 ROUTES, and from the Swedish Research Council for Environment, Agricultural Sciences and Spatial Planning (FORMAS) under grant agreement No. 2012-1122.

\section{Figures}

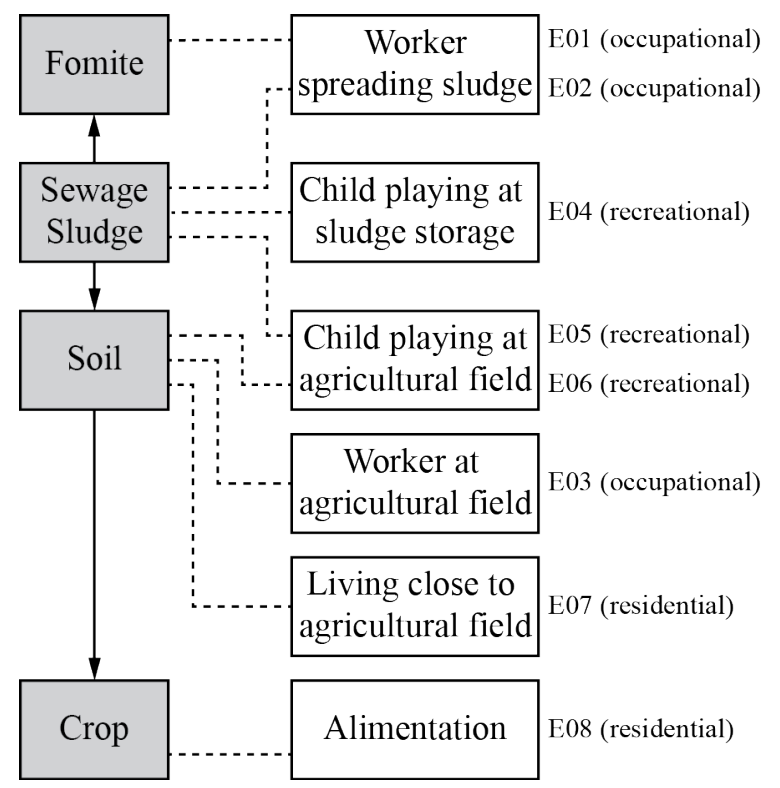

Fig. 1 Overview of fate, transport, and exposure pathways 
P3

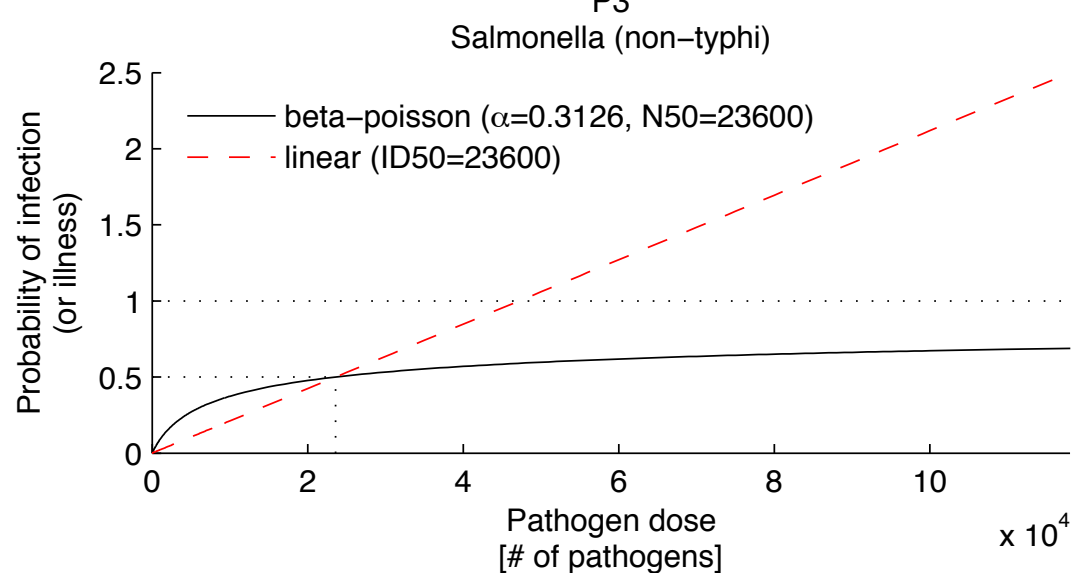

Fig. 2 Dose-response models for non-typhi salmonella (P3). See Online Resource 1 for the respective doseresponse models of the remaining reference pathogens considered in this study

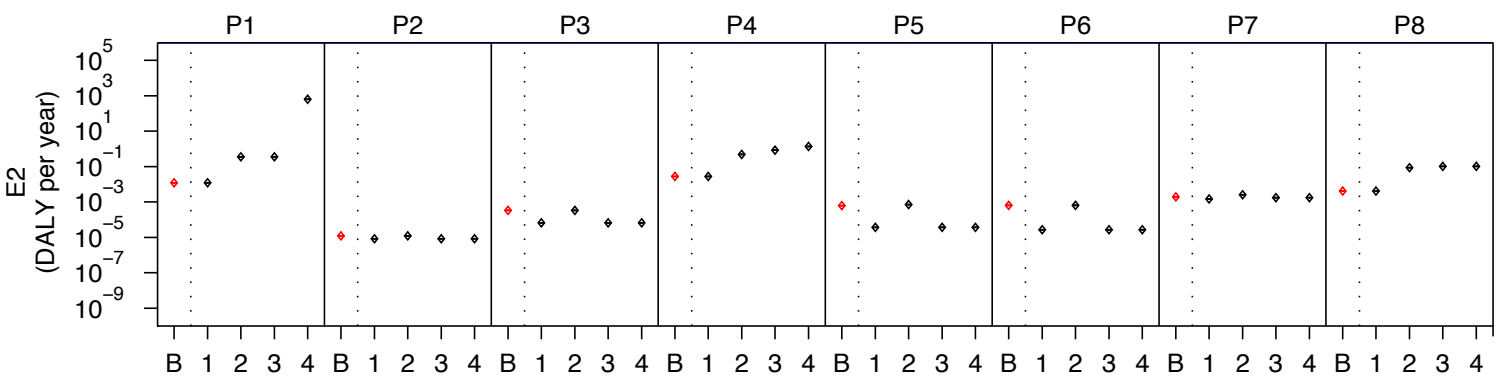

Fig. 3 Calculation results for the different modelling approaches per pathogen for exposure pathway E2 (ingestion of treated sewage sludge by worker during sludge spreading). Red dots (left of the dotted lines) represent the baseline model variant BL (denoted as B in the figure). Black dots (right of the dotted lines) represent model variants M1-M4 (denoted as 1-4 in the figure), respectively. The respective graphs for all combinations of pathogens and exposure pathways are provided in Online Resource 1. Model variants: BL (baseline, no modifications), M1 (modification 1a), M2 (modification 2), M3 (modifications 1a and 2), M4 (modifications $1 \mathrm{a}, 1 \mathrm{~b}$ and 2)

\section{Tables}

Table 1 Overview of exposure pathways including exposure frequency and individuals exposed

\begin{tabular}{llllll}
\hline ID & Activity type & Specific activity & Exposure & & Receptor \\
\hline E1 & occupational & sludge spreading & fomite & fomite contact & adult \\
E2 & occupational & sludge spreading & treated sludge & ingestion & adult \\
E3 & occupational & working on agricultural field & soil & ingestion & adult \\
E4 & recreational & playing at sludge storage & treated sludge & ingestion & child \\
E5 & recreational & playing on field & treated sludge & ingestion & child \\
E6 & recreational & playing on field & soil & ingestion & child \\
E7 & residential & living close to field & soil & ingestion & adult \\
\hline E8 & residential & alimentation & crops & ingestion & adult \\
\hline
\end{tabular}


This is a peer reviewed manuscript accepted for publication in the International Journal of Life Cycle Assessment. The final publication is available at Springer via $h t t p: / / w w w . d x . d o i . o r g / 10.1007 / s 11367-015-0996-2$.

Table 2 Overview of the different combinations of model modifications applied in different model variants

\begin{tabular}{|c|c|c|c|}
\hline Variant & Modification 1a & Modification $1 \mathrm{~b}$ & Modification 2 \\
\hline $\mathrm{BL}$ & & & \\
\hline M1 & Y & & \\
\hline M2 & & & Y \\
\hline M3 & Y & & $\mathrm{Y}$ \\
\hline M4 & $\mathrm{Y}$ & $\mathrm{Y}$ & $\mathrm{Y}$ \\
\hline
\end{tabular}

Table 3 Pathogen risk estimated using the different model variants

\begin{tabular}{cccc}
\hline Variant & $\begin{array}{c}\text { E1-E8 } \\
\text { Burden of disease } \\
(\text { mean })\end{array}$ & $\begin{array}{c}\text { E1-E7 } \\
\text { Burden of disease } \\
(\text { mean })\end{array}$ & $\begin{array}{c}\text { E8 } \\
\text { Burden of disease } \\
(\text { mean })\end{array}$ \\
\hline BL & 1.3 & 1.3 & $1.3 \times 10^{-6}$ \\
M1 & 0.8 & 0.8 & $1.0 \times 10^{-6}$ \\
M2 & 8.8 & 8.8 & $1.3 \times 10^{-6}$ \\
M3 & 9.3 & 9.3 & $1.0 \times 10^{-6}$ \\
M4 & 783 & 783 & $1.0 \times 10^{-6}$ \\
\hline
\end{tabular}

Table 4 Different calculation approaches and parameter choices for exposure pathway E8. Details regarding the assumptions underlying the choice of parameter values are provided in Online Resource 1. Model results represent an overall burden of disease in DALY

\begin{tabular}{cccccccccccc}
\hline Scenario & $\mathrm{t}_{\mathrm{s}}$ & $\mathrm{t}_{\mathrm{c}}$ & $\mathrm{r}_{\text {ing }}$ & $\mathrm{f}_{\exp }$ & $\mathrm{n}_{\text {ind }}$ & $\mathrm{BL}$ & $\mathrm{M} 1$ & $\mathrm{M} 2$ & $\mathrm{M} 3$ & $\mathrm{M} 4$ & ALT \\
\hline $\mathrm{S} 1$ & 90 & 10 & 292 & 2 & 500 & $1.3 \times 10^{-6}$ & $1.0 \times 10^{-6}$ & $1.3 \times 10^{-6}$ & $1.0 \times 10^{-6}$ & $1.0 \times 10^{-6}$ & n.a. \\
$\mathrm{S} 2$ & 5 & 0 & 292 & 2 & 500 & $1.1 \times 10^{0}$ & $0.8 \times 10^{0}$ & $1.3 \times 10^{0}$ & $1.0 \times 10^{0}$ & $1.0 \times 10^{0}$ & n.a. \\
$\mathrm{S} 3$ & 90 & 10 & 30 & 365 & 5000 & $2.5 \times 10^{-4}$ & $1.8 \times 10^{-4}$ & $2.5 \times 10^{-4}$ & $1.8 \times 10^{-4}$ & $1.8 \times 10^{-4}$ & n.a. \\
$\mathrm{S} 4$ & 90 & 10 & n.a. & n.a. & n.a. & n.a. & n.a. & n.a. & n.a. & n.a. & $1.9 \times 10^{-1}$ \\
\hline
\end{tabular}

$\mathrm{t}_{\mathrm{s}}$ : decay time in soil [d], $\mathrm{t}_{\mathrm{c}}$ : decay time on crop [d], $\mathrm{r}_{\text {ing }}$ : rate of ingestion $\left[\mathrm{g} \mathrm{d}^{-1}\right], \mathrm{f}_{\text {exp }}$ : frequency of exposure [yr $\left.{ }^{-1}\right]$, $\mathrm{n}_{\text {ind }}$ : number of individuals exposed [cap]

\section{References}

Aramaki T, Galal M, Hanaki K (2006) Estimation of reduced and increasing health risks by installation of urban wastewater systems. Water Sci Technol 53(9):247-252

Bengtsson M, Tillman A-M (2004) Actors and interpretations in an environmental controversy: the Swedish debate on sewage sludge use in agriculture. Resour Conserv Recy 42:65-82

Bofill-Mas S, Albinana-Gimenez N, Clemente-Casares P, Hundesa A, Rodriguez-Manzano J, Allard A, Calvo M, Girones R (2006) Quantification and Stability of Human Adenoviruses and Polyomavirus JCPyV in Wastewater Matrices. Appl Environ Microb 72(12):7894-7896.

Brooks JP, McLaughlin MR, Gerba CP, Pepper IL (2012) Land application of manure and class B biosolids: An occupational and public quantitative microbial risk assessment. J Environ Qual 41:2009-2023

Cooper J, Lombardi R, Boardman D, Carliell-Marquet C (2011) The future distribution and production of global phosphate rock reserves. Resour Conserv Recy 57:78-86

Corominas L, Foley J, Guest JS, Hospido A, Larsen HF, Morera S, Shaw A (2013) Life cycle assessment applied to wastewater treatment: state of the art. Water Res 47:5480-5492

Eisenberg JN, Brookhart A, Rice G, Brown M, Colford JM Jr (2002) Disease transmission models for public health decision making: Analysis of epidemic and endemic conditions caused by waterborne pathogens. Environ Health Persp 110(8):783-790

Eisenberg JN, Soller JA, Scott J, Eisenberg DM, Colford JM Jr (2004) A dynamic model to assess microbial health risks associated with beneficial uses of biosolids. Risk Anal 24(1):221-236

Eisenberg JN, Moore K, Soller JA, Eisenberg DM, Colford JM Jr (2008) Microbial risk assessment framework for exposure to amended sludge projects. Environ Health Persp 116(6):727-733

Gale P (2005) Land application of treated sewage sludge: quantifying pathogen risks from consumption of crops. J Appl Microbiol 98:380-396 
This is a peer reviewed manuscript accepted for publication in the International Journal of Life Cycle Assessment. The final publication is available at Springer via $h t t p: / / w w w . d x . d o i . o r g / 10.1007 / s 11367-015-0996-2$.

Gao T, Wang XC, Chen R, Ngo HH, Guo W (2015) Disability adjusted life year (DALY): A useful tool for quantitative assessment of environmental pollution. Science of the Total Environment 511:268-287

Goedkoop MJ, Heijungs R, Huijbregts M, De Schryver A, Struijs J, Van Zelm R (2009) ReCiPe 2008, A life cycle impact assessment method which comprises harmonised category indicators at the midpoint and the endpoint level. First edition Report I: Characterisation.

Haas CN, Rose JB, Gerba CP (2014) Quantitative Microbial Risk Assessment, 2nd Edition. Wiley.

Harder R, Heimersson S, Svanström M, Peters GM (2014) Including pathogen risk in life cycle assessment of wastewater management - Part 1: Estimating the burden of disease associated with pathogens. Environ Sci Technol 48(16):9338-9445

Hauschild MZ, Jolliet O, Huibregts MAJ (2011) A bright future for addressing chemical emissions in life cycle assessment. International Journal of Life Cycle Assessment 16:697-700

Hauschild MZ, Goedkoop M, Guinée J, Heijungs R, Huijbregts M, Jolliet O, Margni M, De Schryver A, Humbert S, Laurent A, Sala S, Pant R (2013) Identifying best existing practice for characterization modeling in life cycle impact assessment. Int J Life Cycle Ass 18(3):683-697

Heimersson S, Harder R, Peters GM, Svanström M (2014) Including pathogen risk in life cycle assessment of wastewater management - Part 2: Quantitative comparison of potential impacts of pathogens to other impacts on human health. Environ Sci Technol 48(16):9446-9453

Huibregts M, Hauschild M, Jolliet O, Margni M, McKone T, Rosenbaum RK, van de Meent D (2010) USEtox ${ }^{\mathrm{TM}}$ user manual.

Kobayashi Y, Peters GM, Ashbolt NJ, Heimersson S, Svanström M, Khan SJ (2015) Global and local health burden trade-off through the hybridisation of quantitative microbial risk assessment and life cycle assessment to aid water management. Water Res 79:26-38

Larsen HF, Olsen SI, Hauschild M, Laurent A (2009) NEPTUNE, New sustainable concepts and processes for optimization and upgrading municipal wastewater and sludge treatment, Work Package 4 - Assessment of environmental sustainability and best practice, Deliverable 4.2 - Methodology for including specific biological effects and pathogen aspects into LCA. Lyngby, Denmark: Technical University of Denmark.

Lougheed T (2011) Phosphorus paradox - scarcity and overabundance of a key nutrient. Environ Health Persp 119(5):A208-A213

Murray C (1994) Quantifying the burden of disease: the technical basis for disability-adjusted life years. B World Health Organ 72:429-445

Neset TS, Cordell D (2012) Global phosphorus scarcity: Identifying synergies for a sustainable future. J Sci Food Agr 92:2-6

Rosenbaum RK, Huibregts MAJ, Henderson AD, Margni M, McKone TE, Van de Meent D, Hauschild MZ, Shaked S, Li DS, Gold LS, Jolliet O (2011) USEtox human exposure and toxicity factors for comparative assessment of toxic emissions in life cycle analysis: sensitivity analysis to key chemical properties. Int J Life Cycle Ass 16:710-727

Sales-Ortells H, Medema G (2015) Microbial health risks associated with exposure to stormwater in a water plaza. Water Res 74:34-46

Schoen ME, Xue X, Hawkins TR, Ashbolt NJ (2014) Comparative human health risk analysis of coastal community water and waste service options. Environ Sci Technol 48(16):9728-9736

Soller JA (2009) The potential implications of person-to-person transmission of viral infection for US EPA's Groundwater Rule. J Water Health 7(2):208-223.

Westrell T, Schönning C, Stenström TA, Ashbolt NJ (2004) QMRA (quantitative microbial risk assessment) and HACCP (hazard analysis and critical control points) for management of pathogens in wastewater and sewage sludge treatment and reuse. Water Sci Technol 50(2):23-30

Yoshida H, Christensen TH, Scheutz C (2013) Life cycle assessment of sewage sludge management: A review. Waste Manage Res 31(11):1083-1101 